\title{
Somatic embryogenesis in anther-derived fast-growing callus as a long-term source for doubled-haploid production of coconut (Cocos nucifera L.)
}

\author{
PIP Perera $^{1^{*}}$, R Pathirana ${ }^{2}$ and VRM Vidhanaarachchi ${ }^{3}$ \\ ${ }^{1}$ Department of Horticulture and Landscape Gardening, Faculty of Agriculture and Plantation Management, Wayamba University \\ of Sri Lanka, Makandura, Gonawila. \\ ${ }^{2}$ Plant and Food Research Australia Pty Ltd., Waite Campus Research Precinct-Plant Breeding, Urrbrae, Australia. \\ ${ }^{3}$ Tissue Culture Division, Coconut Research Institute, Lunuwila.
}

\begin{abstract}
Cocos nucifera, one of the most important plantation crops is cross pollinated and has a diploid chromosome complement of $2 \mathrm{n}=2 \mathrm{x}=32$. Doubled-haploid coconut plants are produced at low frequency through anther culture. Nonembryogenic fast-growing calli (FGC) are also produced in anther culture. The present study was undertaken to induce embryogenic calli from these FGC and to test their origin. The FGC were subjected to heat pretreatment at $38{ }^{\circ} \mathrm{C}$ for 3 and 6 days and cultured on three media with different plant growth regulator combinations in liquid, solid and liquid layered on solid (layered) culture, and with different sucrose concentrations. Highest callogenesis and weight increase in FGC was achieved after heat pretreatment of intact FGC cultured in solid Eeuwen's $\mathrm{Y}_{3}$ medium supplemented with $100 \mu \mathrm{M}$ 2,4-dichlorophenoxyacetic acid. Weight increase of FGC was negatively correlated with sucrose concentration. Incorporation of cytokinins facilitated the conversion of FGC to embryogenic callus. Histological studies revealed that these embryogenic calli consisted of a cambium-like zone, a characteristic feature of embryogenic calli. Flow cytometry confirmed that embryogenic calli derived from FGC originated from reduced microspores. Therefore, FGC are a good source of explant for the production of doubled-haploid plants of coconut over an extended period.
\end{abstract}

Keywords: Breeding, callogenesis, flow cytometry, histology, hybrid, in vitro culture.

\section{INTRODUCTION}

The coconut palm (Cocos nucifera L.) is one of the most important perennial tropical plantation crops in the world. Coconut is monoecious with an abundance of staminate flowers and a few pistillate flowers borne on large axillary spadices (Perera et al., 2010). The palm is protandrous and cross pollination is mainly by insects, although wind can also play an important role in some environments (Melendez-Ramirez et al., 2004; Arzani et al., 2005). Self-pollination is less common in Tall cultivars (Melendez-Ramirez et al., 2004). Coconut is conventionally propagated only by seeds, and population breeding through mass selection following mass, controlled or hand pollination has been established in several countries (Labouisse et al., 2004; Perera \& Ekanayake, 2008). Considering the perennial nature of the palm, there is a high demand for uniform, vigorous, elite planting materials for plantation establishment.

The heterozygous nature of coconut means the production of homozygous lines would be useful for breeding, allowing recombination of specific characters into different hybrids. Self-pollination to establish homozygous lines has been attempted (Thomas et al.,

\footnotetext{
*Corresponding author (panawalageindra@gmail.com; (iD https://orcid.org/0000-0003-3302-2778)
} 
2012). However, the development of highly homozygous lines for a hybrid seed production programme will take many decades, because of the long breeding cycle. The efficient production of doubled-haploid (DH) plants using reduced gametes offers opportunities for exploiting heterosis through development of homozygous parents for delivery of new varieties via $\mathrm{F}_{1}$ hybrid seed (Hocher et al., 2005; Pathirana et al., 2011). Identification of microspore development stages for effective production of haploids is important and in coconut cv. 'Sri Lanka Tall' it is three weeks before splitting of the spadix, which corresponds to late uninucleate stage microspores (Perera, 2003). Plant growth regulator (PGR) concentrations in the media have also been optimised for exploiting the androgenic potential of this cultivar and haploid plants have been generated via embryogenesis, albeit at low rates (Perera et al., 2009). Flow cytometry and simple sequence repeats (SSR) marker analyses have shown that the embryo-derived plants are haploid, or diploid and homozygous (Perera et al., 2008).

Among the different types of anther-derived structures such as embryogenic calli and embryos, occurrence of fast-growing calli (FGC; about $1 \%$ ) has been reported in cultured coconut anthers (Perera et al., 2008). Callus texture is dependent on the type of explant used for the initiation of callogenesis (Montoro et al., 1993). Different explant types have been used for the initiation of FGC in different plant species. FGC have been observed to arise from the inner integument of immature seeds in Hevea brasiliensis (Montoro et al., 1993; Sushamakumari et al., 2000), immature embryos in Triticum aestivum (Li et al., 1999), seeds in Spinacia oleracea (Xiao et al., 1997), Boerhaavia paniculata (Souza et al., 2014) and petiole in Rudgea jasminoides (Stella \& Braga, 2002). Callus friability which favours callus dispersion in liquid medium is controlled by genetic factors (Qiao et al., 2012) as well as by the composition of the culture medium (Sushamakumari et al., 2000; Tripathi et al., 2012). The ratio of PGR, especially that of synthetic auxin and cytokinin have been demonstrated as important in determining the texture of the callus in many plant species (Akaneme \& Eneobong 2008; Li et al., 2012). Amino acids such as proline can also influence the texture of callus (ElNaggar 2011; Rattana et al., 2012). Among other factors that control the friability of callus cultures, silver nitrate, calcium, cation ratio and sucrose concentration appear to be important (Vain et al., 1989; Montoro et al., 1993). The exact reason for the occurrence of FGC in coconut is unclear, however occurred at a low frequency in coconut (Perera et al., 2008).
Anther-derived FGC can be a good additional source of haploid or DH plants, as dealing with haploid callus over an extended period has an advantage considering the difficulties in establishing anther-derived callus. These can also serve as source material for mutation induction and gene discovery. Those haploid cell lines could also be of great value in construction of molecular linkage maps in highly heterozygous plants like coconut. Considering their texture, FGC could also serve as initial material in applications such as protoplast and cell suspension cultures for more advanced studies. Thus, the present study was undertaken to improve the growth rates and to explore the embryogenic potential of the anther-derived FGC, and to understand their origin.

\section{METHODOLOGY}

\section{Experimental material}

Fast growing calli were induced in the cultured anthers of cv. 'Sri Lanka Tall' on modified Eeuwen's $Y_{3}$ liquid medium (Karunaratne et al., 1985) supplemented with $100 \mu \mathrm{M}$ 2,4-dichlorophenoxyacetic acid (2,4-D), $0.1 \%$ activated charcoal and $9 \%(\mathrm{w} / \mathrm{v})$ sucrose using the protocol reported by Perera et al. (2008). While the embryos/embryogenic calli derived from the cultured anthers of three different batches were used for regenerating DH plants, the FGC lines initiated from 10 anthers of those cultures were used as the explants for the present study. Anthers containing FGC were subcultured onto the same medium containing $4 \%$ sucrose and maintained for one month for multiplying the callus lines. Two such multiplication cycles were run to make them sufficient for initiating the experiments. The research was conducted at the Tissue Culture Division, Coconut Research Institute, Lunuwila, Sri Lanka.

\section{Culture media}

Modified Eeuwen's $Y_{3}$ medium supplemented with $6 \%$ sucrose $(\mathrm{w} / \mathrm{v}), 0.1 \%$ activated charcoal $(\mathrm{w} / \mathrm{v})$ and 0.25 $\%$ phytagel (w/v) was used as the basal medium (BM) in all experiments, unless otherwise mentioned. After adjusting the $\mathrm{pH}$ to 5.8 , activated charcoal and phytagel were added to the medium and autoclaved at $121{ }^{\circ} \mathrm{C}$ for 20 min. Five Petri plates per treatment, each representing a replicate, were used in all experiments unless otherwise stated. Eight $0.1-0.2 \mathrm{mg}$ FGC pieces were cultured onto each Petri plate containing the culture medium. Embryos derived from FGC were transferring to $\mathrm{BM}$ and maintained for one month before transfer to $\mathrm{BM}$ supplemented with $25 \mu \mathrm{M}$ 6-benzylaminopurine (BAP), 
$0.45 \mu \mathrm{M}$ gibberellic acid $\left(\mathrm{GA}_{3}\right)$ and $0.1 \mu \mathrm{M}$ 2,4-D for embryo conversion and regeneration (regeneration medium). Cultures were maintained in the dark at $28 \pm 1{ }^{\circ} \mathrm{C}$ until converted and then exposed to light $\left(25 \mu \mathrm{molm}^{-2} \mathrm{~s}^{-1}\right)$ with a $16 / 8 \mathrm{~h}$ photoperiod. Chemicals for tissue culture were purchased from Sigma Chemical Co., St Louis, Missouri, USA.

\section{Induction of somatic embryogenesis}

FGC lines originated from 10 different anthers as mentioned above were used for testing the effect of heat pretreatment for inducting embryogenesis. In the first experiment heat at $38{ }^{\circ} \mathrm{C}$ for $0,1,7,24,48,72$ and $144 \mathrm{~h}$ was applied to the culture plates containing the multiplied FGC (hereafter termed as intact FGC). Then, equal amount of FGC was cultured onto the modified Eeuwen's $\mathrm{Y}_{3}$ solid medium supplemented with $50 \mu \mathrm{M}$ 2,4-D. In the second experiment, the small clumps from the multiplied FGC were cultured onto the same medium mentioned for the first experiment and heat shock was applied at $38{ }^{\circ} \mathrm{C}$ for $0,0.5,1,2,3,5,7$ and $24 \mathrm{~h}$. In both experiments, cultures were maintained for one month in the dark. Based on the results of the above experiments, the intact FGC subjected to heat pretreatment at $38{ }^{\circ} \mathrm{C}$ for $72 \mathrm{~h}$ was used for further experiments on improving callogenesis and for inducing embryogenesis.

\section{Effect of medium composition and physical status}

Three culture media, namely, modified Eeuwen's $\mathrm{Y}_{3}$ (Karunaratne et al., 1985), CRI 72 (Karunaratne \& Periyapperuma, 1989) and MS (Murashige \& Skoog, 1962) in combination with the physical status of the culture media (liquid, solid or layered) were tested. Layered cultures were established by placing a thin layer of sterile liquid medium $(20 \mathrm{~mL})$ onto the solid medium. All the media were supplemented with $100 \mu \mathrm{M}$ 2,4-D and $4 \%$ sucrose.

\section{Optimising plant growth regulators, medium physical status and sucrose concentration}

Four experiments were conducted to optimise the concentration of PGR in the culture medium, its physical status and medium sucrose concentration for efficient somatic embryogenesis of FGC. The first experiment in this series was a $3 \times 3$ factorial experiment in five replicates that used BM supplemented with $100 \mu \mathrm{M}$ 2,4D. The first factor consisted of three concentrations $(0$, $10,100 \mu \mathrm{M}$ ) of $\alpha$-naphtheleneacetic acid (NAA) and the second factor was the physical status of the medium; liquid, solid or layered culture. In the second experiment, nine treatments consisted of BM supplemented with 0 , 10 and $100 \mu \mathrm{M}$ 2,4-D and N6-(2-isopentenyl) adenine (2-iP) in all possible combinations. The third experiment had a similar design to the second, except that 2-iP was replaced with kinetin. In the fourth experiment of this series, four concentrations of sucrose $(4,6,9,12 \%)$ were tested using BM supplemented with $100 \mu \mathrm{M} 2,4-\mathrm{D}$. The number of embryogenic calli produced in cultured FGC was recorded after 3 months in each experiment.

\section{Data analysis}

Experiments were conducted in a completely randomised design. All experiments were repeated a minimum of two times. The fresh weight gain of the cultured FGC in each culture plate was recorded after three months of culture initiation. ANOVA procedure was performed on the square root data using statistical analysis system software (SAS, 1999). Mean separation was done using least significant difference (LSD).

\section{Histological studies}

Histological studies were conducted to identify the cellular arrangement of the anther-derived FGC and the FGC-derived structures. The samples were fixed in a solution of $50 \%$ ethanol: $10 \%$ glacial acetic acid: $10 \%$ formaldehyde - 18:1:1 (v/v) for $72 \mathrm{~h}$. Then the samples were dehydrated in a graded series of 50,70, 95 and $100 \%$ ethanol for $2 \mathrm{~h}$ each followed by ethanolbutanol solution $(1: 1 \mathrm{v} / \mathrm{v})$ for $1 \mathrm{~h}$ and $100 \%$ butanol for $72 \mathrm{~h}$. Butanol was used to facilitate further impregnation of paraplast. The period in each solution was extended for larger structures. The samples were then transferred to $100 \%$ butanol/melted paraffin wax (CDH New Delhi - melting point at $\left.60{ }^{\circ} \mathrm{C}\right)$ solution $(1: 1)(\mathrm{v} / \mathrm{v})$ and maintained at $60{ }^{\circ} \mathrm{C}$ for $3 \mathrm{~d}$, changing the solution once each day. Afterwards, the samples were transferred to $100 \%$ paraffin wax for $3 \mathrm{~d}$, with two changes per day at $60{ }^{\circ} \mathrm{C}$. Infiltrated samples were sealed in plastic moulds with fresh, melted paraffin wax.

Wax-embedded samples were sectioned at $5 \mu \mathrm{m}$ in thickness using a manual microtome (OSK 9770 Rotary Microtome, Japan). The complete series of ribbon sections were transferred to warm water $\left(\sim 50{ }^{\circ} \mathrm{C}\right)$ and mounted on glass slides covered with a thin smear of Mayer's adhesive, prepared by adding a few drops of sodium salicylate into a mixture of egg white and glycerol (1:1). Then the slides were maintained at $45^{\circ} \mathrm{C}$ until staining. Prior to staining, wax was removed from 
the slides using sulfur-free xylene. The slides were transferred to a solution containing equal parts of xylene and absolute alcohol for $10 \mathrm{~min}$, re-hydrated with four rinses in 100, 90, 70, and $50 \%(\mathrm{v} / \mathrm{v})$ ethanol $(5 \mathrm{~min}$ in each) and washed gently with distilled water. De-waxed slides were stained with protein-specific naphthol blue black. After draining the excess stain, the stained slides were dried at $45{ }^{\circ} \mathrm{C}$. The prepared slides were observed under a light microscope (LEICA CME, Germany) equipped with a camera.

\section{Flow cytometer analysis}

FGC derived from 10 cultured anthers, which were used for initiating the aforementioned experiments were simultaneously used for ploidy analysis. Extraction of nuclei and the analysis were done according to the protocol described by Pathirana and Eason (2006). Nuclear DNA content was determined using a Partec PAII flow cytometer (Partec, Munster, Germany) with UV excitation at the New Zealand Institute for Plant and Food Research Limited, Lincoln, New Zealand. Samples were analysed using the leaves of coconut cv. Sri Lanka Tall as a diploid control, and hexaploid Hieracium as internal standards prepared by co-chopping with the experimental embryogenic material. The ploidy level was estimated using Partec FloMax software by comparing the parental nuclear DNA content with that of the sample.

\section{RESULTS AND DISCUSSION}

Anther-derived FGC in the androgenesis induction medium were highly friable and appeared morphologically like a clumped powder (Figure 1a). The frequency of anthers giving rise to FGC was very low, in most cases less than $1 \%$. The FGC have a very high multiplication rate where the sub-cultured Perti plate is fully covered by the calli within a multiplication period of one month. Therefore, material was sufficiently available for repeating the experiments. They were used in different experiments in order to induce embryogenesis and to test multiplication rates to understand the feasibility of using FGC for DH plant production.

\section{Effect of heat pretreatment on the induction of embryogenesis in FGC}

Observations of the first experiment revealed that the heat pretreatment of the intact FGC is better than the pretreatment after extracting them and plating on fresh media for conversion of FCG to embryogenic status. Pretreatment of intact callus at $38{ }^{\circ} \mathrm{C}$ for 72 hours and
144 hours before subculture stimulated the conversion of callus into embryogenic masses as observed by a change in texture and organising into globular structures (Figure1b) whereas lower durations did not show any positive response other than multiplying the FGC. Seventy-two hours (3 days) of heat pretreatment resulted in $60 \%$ conversion of FCG to embryogenic masses, whereas 144 hours (6 days) of pretreatment was sufficient to convert all the FGC. Application of heat shock after extracting the FGC in the second experiment resulted in callus browning and reduced growth. It could have been caused by cell death due to faster removal of water from the fragile cells disturbed during extraction and subsequent application of high temperature.

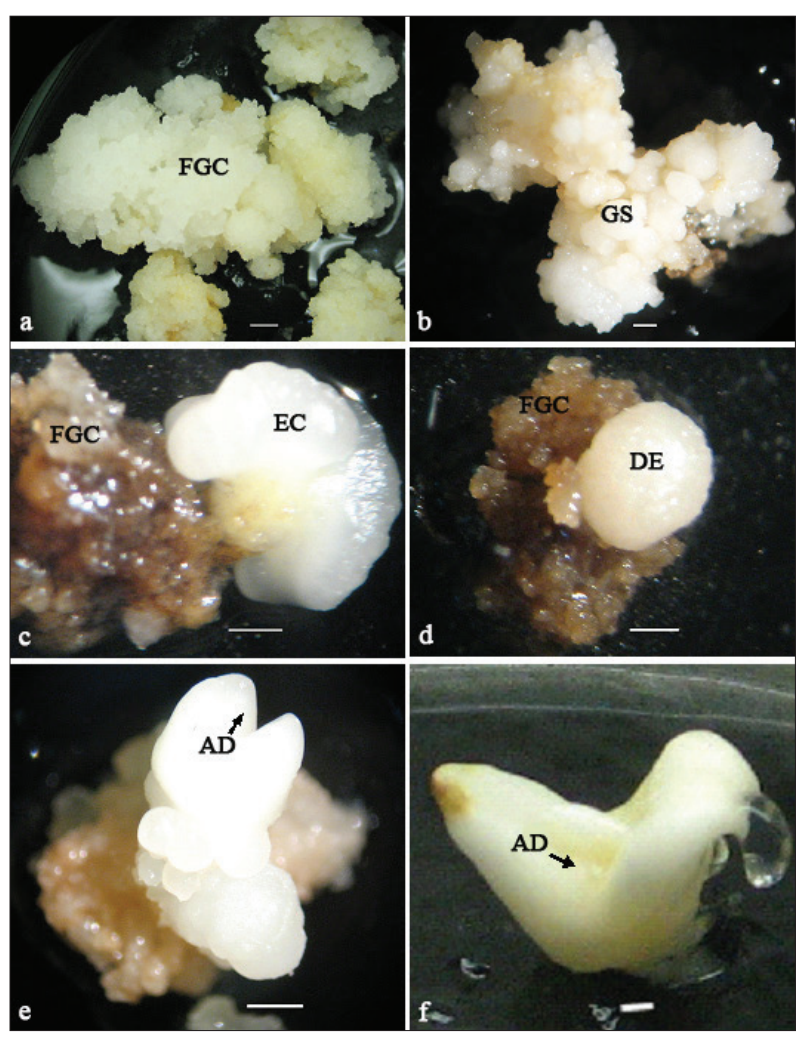

Figure 1: Embryogenesis in anther-derived fast-growing calli (FGC) in Cocos nucifera $\mathrm{L}$.

(a) clumps of fragile FGC; (b) changed texture of the FGC subcultured into callus induction medium after incubating at $38{ }^{\circ} \mathrm{C}$ for 3 days. Note the formation of the distinct globular structures (GS). (c) An embryogenic callus (EC) with characteristic frilly structure; (d) direct embryo (DE); (e) sprouted embryo. Note the apical dome (AD). (f) A germinating embryo. Note the apical dome emerging through the haustorium tissue $(\mathrm{Bar}=1 \mathrm{~mm})$ 


\section{Effect of the composition of culture medium and its physical status}

The nutrient composition of the culture medium and its physical status had a highly significant effect (Figure $2 \mathrm{a} ; \mathrm{p}<0.0001 ; \mathrm{LSD}=0.87$ ) on the fresh weight gain of cultured FGC. FGC growing on modified Eeuwen's $\mathrm{Y}_{3}$ medium recorded the largest mass increase. The physical state of the culture medium also had a highly significant effect on the fresh weight gain with solid medium resulting in significantly better growth than the liquid or layered culture media (Figure $2 \mathrm{a}$ ). Two factorial variance analysis confirmed a significant interaction between the culture medium and its physical status for fresh weight gain of FGC (Figure 2a).
Formation of embryogenic calli (Figure 1c) or embryos with similar morphology reported by Perera et al. (2020) (Figure 1d) was observed in all three media. However, all the cultured FGC converted to embryogenic calli only in modified Eeuwen's $\mathrm{Y}_{3}$ medium, whereas in CRI 72 and MS media, the conversion rate was only $40 \%$ after three months of culture. On solid media, all FGC converted to embryogenic callus whereas in layered cultures conversion to embryogenic state was $80 \%$. Liquid cultures completely failed to produce embryogenic callus from FGC.

CRI 72 culture medium has been formulated specifically for coconut tissue culture (Karunaratne \& Periyapperuma, 1989) and used successfully for

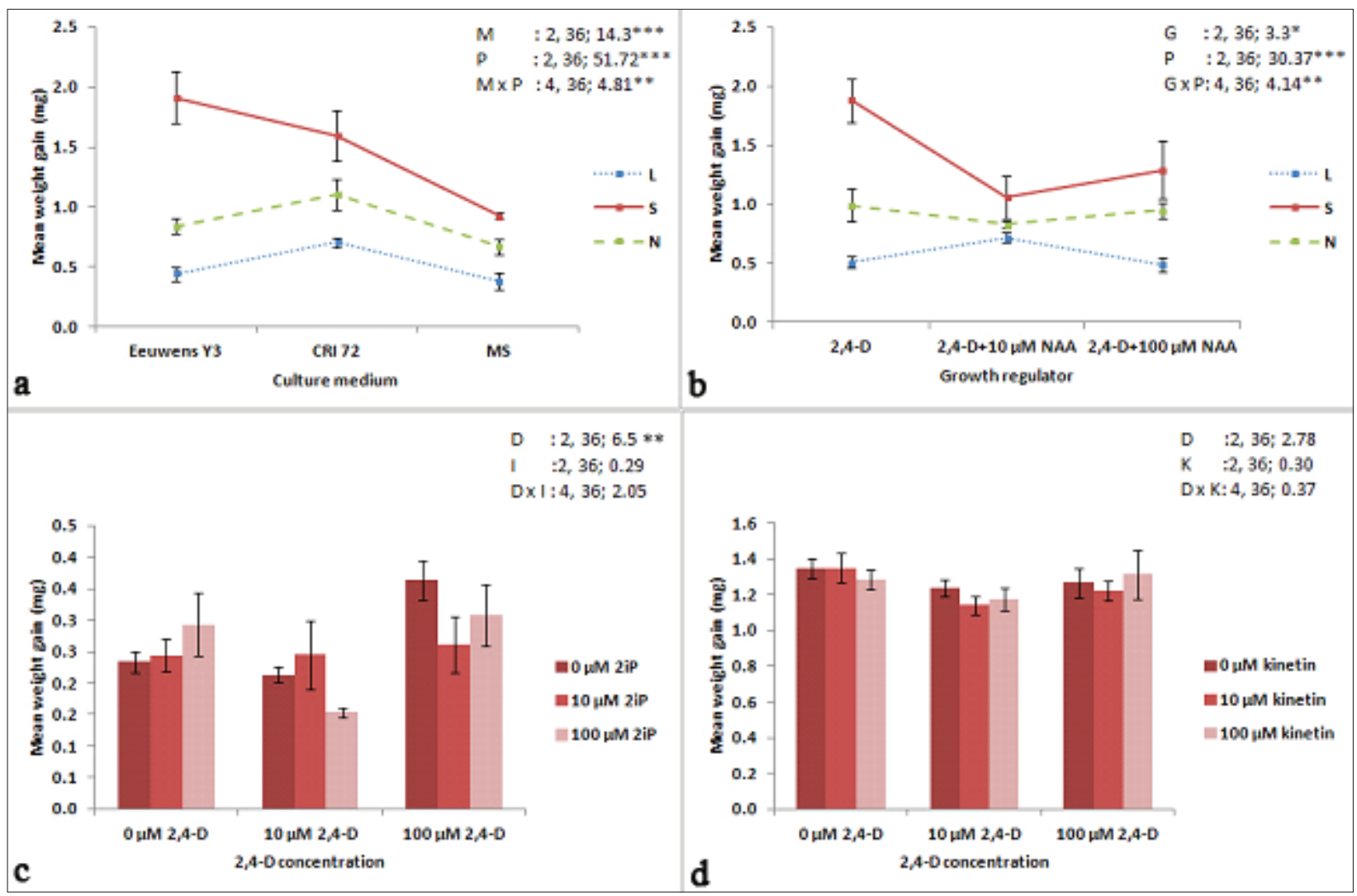

Figure 2: Effect of media composition, physical state and plant growth regulator combinations on weight gain of fast growing calli of Cocos nucifera $\mathrm{L}$. after three months of culture initiation. Degrees of freedom (DF) followed by the residual DF and the $\mathrm{F}$ value with the significance level are indicated in figure. (a) effect of media composition (M) and physical state of culture medium (P) (L - liquid, S solid, N - layered liquid over solid medium culture); (b) effect of growth regulator (G) combination, NAA and 2,4-D (100 $\mu \mathrm{M})$ with the physical status of culture medium (P); (c) effect of 2-iP (I) in combination with 2,4-D (D); (d) effect of kinetin (K) in combination with 2,4-D. Bars represent the standard error. 
callus induction and somatic embryogenesis using explants such as immature embryos (Fernando \& Gamage, 2000), plumules (Fernando et al., 2003) and ovaries (Perera et al., 2007). However, it was not effective in cultured anther-derived FGC in the present research. Highest weight gain and the production of embryogenic calli were recorded in modified Eeuwen's $\mathrm{Y}_{3}$ medium. It contains more amino acids (asparagine, glutamine and arginine) as well as more $\mathrm{NH}_{4} \mathrm{Cl}, \mathrm{KCl}$ and $\mathrm{NiCl}$ than the CRI 72 medium. This could have contributed to the positive response of anther-derived FGC cultured in modified Eeuwen's $\mathrm{Y}_{3}$ medium. MS medium has been used as the basal medium for induction of callogenesis in many crop species, such as pepper (Capsicum annum; Kim et al., 2004), cauliflower (Brassica oleracea var. Botrytis; Metwali \& Al-Maghrabi, 2012), rice (Oryza sativa; Pathirana et al., 2002) and asparagus (Asparagus officinalis; Peng \& Wolyn, 1999). However, in the present study MS medium was not effective in terms of either the production of embryogenic calli or to increase the mass of FGC. Modified Eeuwen's $Y_{3}$ medium was the best for fresh weight gain and the induction of embryogenesis in anther-derived FGC and thus it was used as the BM for rest of the experiments.

\section{Effect of plant growth regulators}

Plant growth regulators can be used for modifying the callus type (Carrier et al., 1990). The auxin found to be most critical for clonal propagation and $\mathrm{DH}$ production in coconut using plumule, unfertilised ovary and anthers is 2,4-D (Fernando et al., 2000; Perera et al., 2007). Thus, in the present study the effect of three PGR, NAA, 2-iP and kinetin in combination with 2,4-D was investigated in separate experiments with the aim of inducing embryogenesis in the non-embryogenic FGC.

\section{Effect of NAA}

The weight gain FGC in response to different concentrations of NAA is given in Figure 2b. Analysis of variance revealed a highly significant treatment effect on the weight gain of FGC (Figure 2b). Significant effects of NAA and the physical state of the culture medium were identified. Modified Eeuwen's $Y_{3}$ solidified medium supplemented with $100 \mu \mathrm{M} 2,4-\mathrm{D}$ as the only PGR resulted in the highest weight gain (3.67 g in 3 months) in cultured FGC, which was significantly different from all other treatments (Figure 2b; $p<0.0001$; LSD $=0.59$ ). Nevertheless, the production of embryogenic calli was improved by incorporating NAA into the culture medium, the highest being $60 \%$ conversion in the medium supplemented with $100 \mu \mathrm{M}$ NAA. The highest frequency of callus induction from the cultured anthers has been observed in medium supplemented with $100 \mu \mathrm{M}$ 2,4-D and $100 \mu \mathrm{M}$ NAA in the basal androgenesis induction medium of coconut (Perera et al., 2009).

Confirming the results of the previous experiment, solidified culture medium was the best for multiplication of FGC (LSD = 0.59; Figure 2b). This held true for all the three media tested; modified Eeuwen's $\mathrm{Y}_{3}$, MS and CRI 72. Solidified or layered cultures gave rise to embryogenic callus in all the plates, whereas only $20 \%$ produced embryogenic callus in liquid culture medium. An interaction effect of the presence of PGR in the culture medium and their physical status was also observed (Figure 2b).

\section{Effect of 2,4-D and 2-iP on callus weight gain in FGC and conversion to embryogenic state}

Analysis of variance revealed a significant treatment effect on the weight gain of FGC in the treatments applied; $100 \mu \mathrm{M} 2,4-\mathrm{D}$ alone recording the highest (Figure 2c; $\mathrm{p}$ $<0.05 ; \mathrm{LSD}=0.04)$. The only significant effect noted in this experiment was that of the concentration of 2,4-D. Eventhough the application of 2-iP was not as effective as 2,4-D for fresh weight gain in FGC, it was more effective in the conversion of FGC to embryogenic callus. Media containing either 100 or $10 \mu \mathrm{M} 2-\mathrm{iP}$ in combination with 2,4-D resulted in the conversion of 20 and $40 \%$ FGC to embryogenic status, respectively. A combination of 2-iP and 2,4-D has been shown to be optimal to induce callus/embryos from cultured anthers of coconut (Perera et al., 2009). Induction and multiplication of FGC was effective in the presence of 2,4-D in the culture medium as reported in several other crops including Boerhaavia paniculata (Souza et al., 2014), Clinacanthus nutans (Phua et al., 2016) and Echinacea purpurea (Karimi et al., 2018).

\section{Effect of 2,4-D and kinetin on fresh weight gain of FGC and their conversion to embryogenic state}

Nine different combinations of 2,4-D and kinetin did not result in a significant difference in fresh weight gain of FGC compared with 2,4-D applied alone (Figure 2d). However, incorporation of $100 \mu \mathrm{M}$ kinetin into the medium with 0 or $10 \mu \mathrm{M}$ 2,4-D resulted in embryos in $40 \%$ cultured FGC. When these embryos were maintained in the same medium for another two weeks, they converted in to mature embryos that gave rise to shoots after transferring to regeneration medium (Figure $1 \mathrm{e}$ and 1f). In contrast to FGC, lower kinetin $(10 \mu \mathrm{M})$ and 
higher 2,4-D $(100 \mu \mathrm{M})$ concentrations in the androgenesis induction medium resulted in a significant increase in the frequency of callus and embryo production when anthers were cultured (Perera et al., 2009). The reason could be the carry-over effect of 2,4-D from the initial medium used for induction and multiplication of FGC which contained a high concentration of the same. Similar to the results with coconut in this study, media supplemented with 2,4$\mathrm{D}$ and kinetin favoured the production of embryogenic calli in niger (Guizotia abyssinica; Sarvesh et al.,1993) and cucumber (Song et al., 2007).

Among the tested PGR, $100 \mu \mathrm{M}$ 2,4-D is effective in multiplication of FGC. However, for inducing embryogenesis, NAA $(100 \mu \mathrm{M}), 21 \mathrm{P}(100 \mu \mathrm{M})$ or kinetin $(100 \mu \mathrm{M})$ were effective in combination with different levels of 2,4-D. Embryos containing shoot apical meristem is the characteristic feature for triggering the regeneration pathway. Future research will aim towards achieving plant regeneration from the converted embryos and their deployment in coconut breeding programmes.

Sucrose concentration in the BM supplemented with $100 \mu \mathrm{M}$ 2,4-D had a significant effect on the multiplication rate of FGC (Figure 3). The fresh weight gain of FGC was highest with $4 \%$ sucrose (LSD = 0.19). An inverse relationship was observed between the sucrose concentration and the fresh weight gain of cultured FGC, with higher sucrose concentrations lowering the multiplication rate (Figure 3). In contrast,

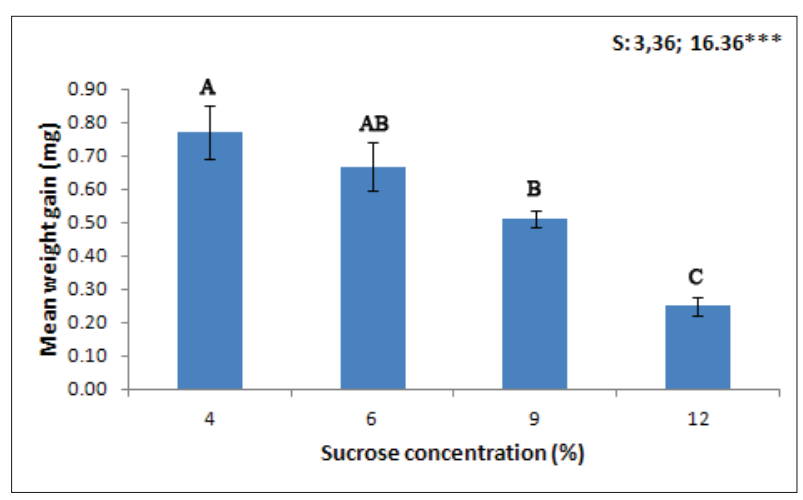

Figure 3: Effect of sucrose concentration (S) on fresh weight gain in cultured fast growing calli in Cocos nucifera L. after four weeks of culture on solid Eeuwen's $Y_{3}$ medium. Degrees of freedom (DF) followed by residual DF and the F value with significance level, is indicated. Error bars represent the standard error. Different letters indicate a significantly different effect on the fresh weight gain at $\mathrm{p}<0.05$. the use of elevated levels of sucrose has been beneficial for microspore embryogenesis in many crops (Montoro et al.,1993; Konieczny et al., 2003) as with the anther culture medium used previously in coconut (Perera et al., 2008). However, in the present research, embryogenesis could not be induced in friable FGC in coconut by using higher concentrations of sucrose in the culture medium. Moreover, high sucrose concentration lowered the multiplication rate of FGC. High frequency of DH generation in anther culture media with $3 \%$ sucrose has been achieved in Gentiana triflora (Pathirana et al., 2011).

\section{Histological analysis}

\section{Fast-growing calli}

Histological analysis of the anther-derived FGC revealed that it consisted of isolated meristematic cell clumps among the masses of non-embryogenic cells (Figure 4a). The clumps were characterised by the presence of high

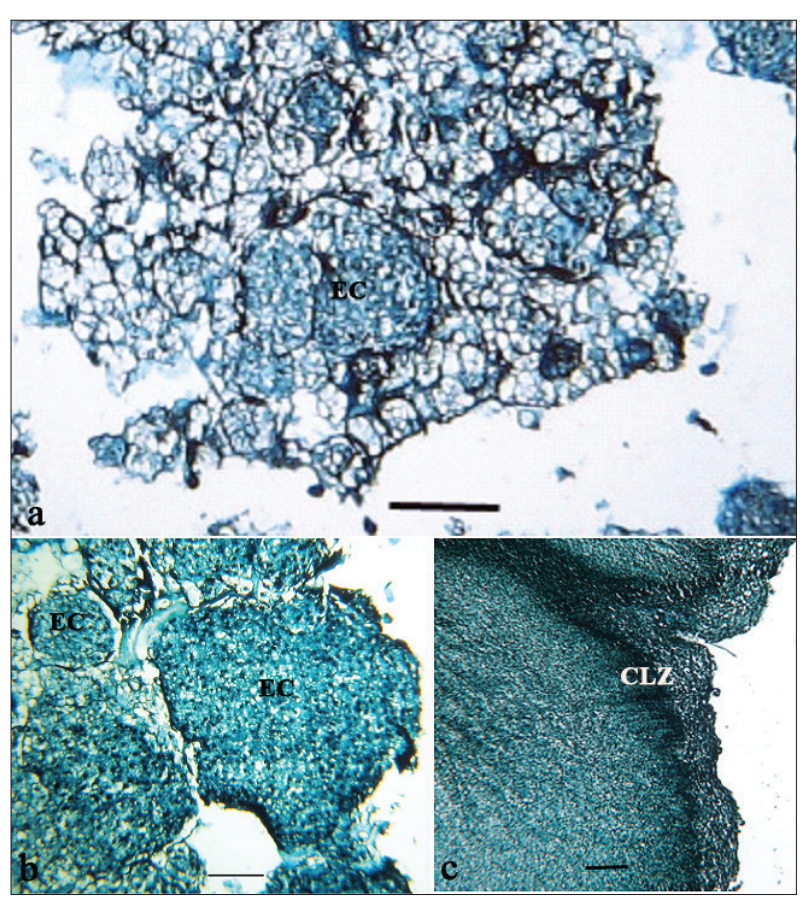

Figure 4: Histology of conversion of fast growing calli of Cocos nucifera L. into embryogenic stage: (a) presence of embryogenic cell clumps (EC) among non-embryogenic cells $($ Bar $=200 \mu \mathrm{m}) ; \quad(b)$ histology of an isolated embryogenic cell clump under high magnification $(\mathrm{Bar}=$ $100 \mu \mathrm{m})$; (c) embryogenic callus with the characteristic features of cambium-like zone (CLZ) (Bar $=250 \mu \mathrm{m})$. 
protein reserves, high nucleus to cytoplasmic ratio and mitotically active nuclei (Figure 4b) that are comparable with the proembryos developed in cultured anthers of coconut (Perera et al., 2007). A large number of these isolated embryogenic pockets were clearly identified over the unstained non-embryogenic cells in the FGC (Figure 4a). As described in the first experiment, the texture could be changed by applying heat shock followed by culturing them onto media with reduced auxin $(50 \mu \mathrm{M})$. Under these conditions, the development of active cell masses predominated over the nonembryogenic masses (Figure 4c).

\section{Callus-like structures}

The compact callus-like structures derived from friable FGC after applying heat shock were analysed to study their cellular arrangement in order to identify the progress in embryogenesis pathway. They consisted of a cambium-like zone (CLZ; Figure 4c), which is a characteristic feature of an embryogenic callus described in ovary-derived multicellular embryos in coconut (Perera et al., 2007). This indicates the potential of converting the meristematic pockets into embryogenic calli. However, this CLZ is thin and the parenchyma cells stained very lightly in contrast to embryogenic callus, indicating a low activity of this tissue.

\section{Embryogenic callus and direct embryos}

Highly embryogenic calli as identified by their morphological features were also microscopically analysed. They consisted of a characteristic CLZ (Figure 4c). As described by Perera et al. (2007), periclinal cell division of the peripheral cells and the anticlinal cell division of the inner parenchyma cells of this zone ensure the growth of the callus. Greater thickness of this meristematic zone is an indication of high cellular activity leading to fast growth and multiplication of the callus.

\section{Flow cytometry analysis}

Different methods are available for testing the ploidy status of calli including cytology by counting the number of chromosomes, molecular analysis using SSR markers and flow cytometric analysis by counting the number of cells containing different DNA contents. The methods of cytology and flow cytometry both will give similar observations on identification of ploidy level, haploid or diploid status. Therefore, flow cytometry analysis was used for detecting the ploidy status of 10 anther-derived FGC lines used in the study.

The DNA content of FGC was compared with the diploid coconuts and with hexaploid Hieracium as an internal standard in which the DNA content is not overlapped with any ploidy level of coconut (Figure 5a). Six of the tested FGC lines resulted in a haploid $(\mathrm{n}=\mathrm{x}=16)$ peak, indicating an origin from reduced microspores. Two lines gave two peaks corresponding to haploid and diploid $(2 \mathrm{n}=2 \mathrm{x}=32)$ DNA contents and another two lines gave three peaks representing haploid, diploid and tetraploid $(4 n=4 x=64)$ DNA contents (Figure $5 b)$.

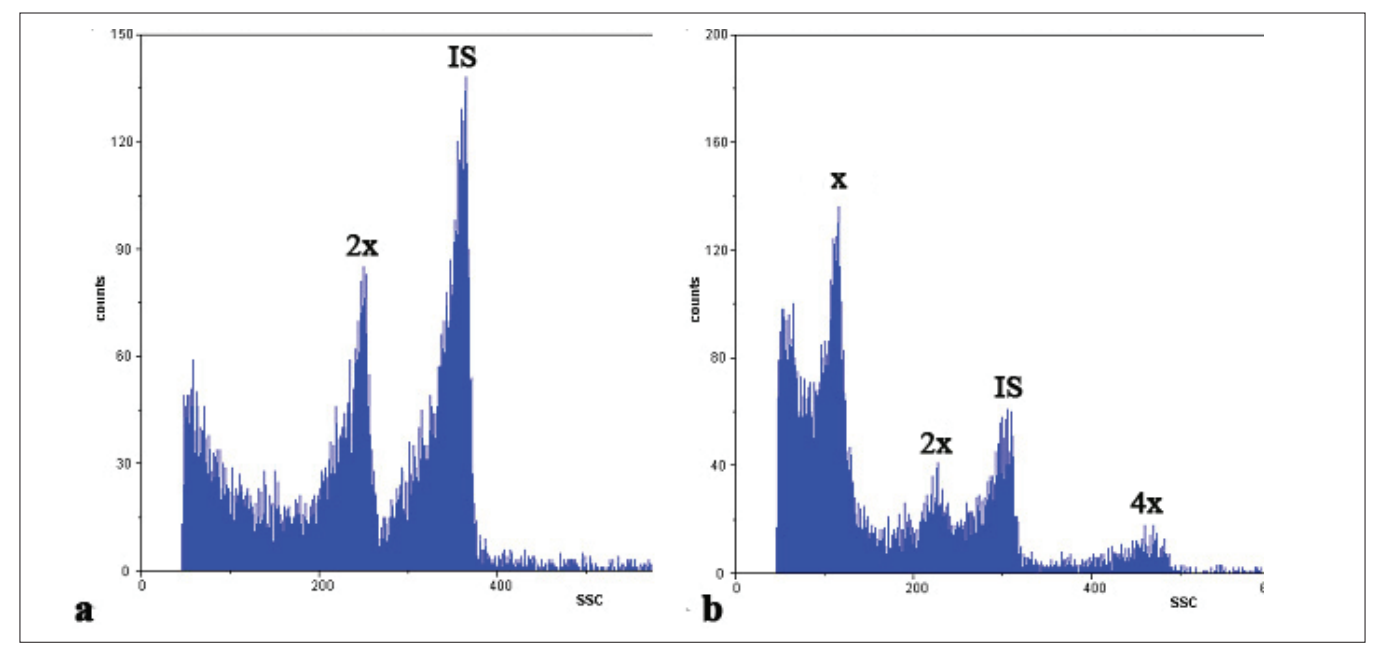

Figure 5: Histograms of flow cytometric analysis of fast growing calli of Cocos nucifera L. (a) Diploid control (2x) and hieracium as the internal standard (IS); (b) FGC with predominating haploid (x) peak and smaller diploid (2x) and tetraploid $(4 \mathrm{x})$ peaks compared to the internal standard. 
Nevertheless, the haploid peak was prominent over the other peaks in all the lines. The presence of a larger haploid peak confirms the haploid origin from reduced male gametes. The presence of diploid and tetraploid peaks is an indication of partial diploidization during cell division, but most likely it could be the result of endoreduplication, often found in fast-dividing cells (Schnittger et al., 2002; Vlieghe et al., 2005). The degree of endoreduplication is thought to correspond to the rate of cell division, with rapid chromosome division causing nuclear and cell division to lag behind, resulting in multinucleate cells with polyploid chromosome counts (Pathirana \& Eason, 2006). Along with flow cytometry analysis, cytological studies will also be included in future research to confirm the ploidy status of FGC and regenerated plants, as the next stage of this research is to produce $\mathrm{DH}$ plants for the breeding programmes.

\section{CONCLUSIONS}

The present study clearly indicated that callus texture could be altered by applying heat stress to anther-derived FGC of coconut, converting those to an embryogenic state by optimising the media and PGR. The feasibility of using heat-pretreated $\mathrm{FGC}$ at $38{ }^{\circ} \mathrm{C}$ for 72 hours or 144 hours to generate embryos was also demonstrated. Eeuwen's $\mathrm{Y}_{3}$ solidified medium supplemented with $100 \mu \mathrm{M}$ kinetin induced direct embryogenesis in nonembryogenic FGC. Furthermore, anther-derived FGC was identified as originating from reduced microspores, which could be used as a starting material for DH plant production in coconut over a long period under controlled laboratory conditions. These FGC could also be used for initiating cell cultures in the production of secondary metabolites and for mutation induction and genomic studies in the future.

\section{Acknowledgement}

The authors wish to thank the staff of the Tissue Culture Division, Coconut Research Institute, Lunuwila, Sri Lanka for assistance in the laboratory work, Dr Ross Bicknell, Plant and Food Research, Lincoln, New Zealand for flow cytometry and Mr. J.D.J.S. Kularatne for statistical analysis and Ms. U.N. Hewawasam for technical assistance.

\section{REFERENCES}

Akaneme F.I. \& Eneobong E.E. (2008). Tissue culture in Pinus caribaea Mor. var. Hondurensis barr. and golf. II: effects of two auxins and two cytokinins on callus growth habits and subsequent organogenesis. African Journal of Biotechnology 7(06): 757-765.

DOI: http://doi.org/10.4314/as.v4i1.1516

Arzani K., Zare-Nahandi F. \& Amiri M.E. (2005). Performance of flowering and fruit set of coconut (Cocos nucifera) palms under the Kish Island environmental conditions of Iran. Indian Journal of Agricultural Sciences 75(11): 731-734.

Carrier D.J., Cosentino G., Neufeld R., Rho D., Weber M. \& Archambault J. (1990). Nutritional and hormonal requirements of Ginkgo biloba embryo-derived callus and suspension cell culture. Plant Cell Reports 8: 635-638. DOI: https://doi.org/10.1007/BF00269981

El-Naggar H.M. (2011). Phenylalanine ammonia-lyase (PAL) gene activity in response to proline and tyrosine in rosemary callus culture. African Journal of Biotechnology 11(01): 159-163. DOI:https://doi.org/10.5897/AJB11.2585

Fernando S.C. \& Gamage C.K.A. (2000) Abscisic acid induced somatic embryogenesis in immature embryo explants of coconut ( L.). Plant Science 151(02): 193-198. DOI: https://doi.org/10.1016/S0168-9452(99)00218-6

Fernando S.C., Verdeil J.L., Hocher V., Weerakoon L.K. \& Hirimburegama K. (2003). Histological analysis of plant regeneration from plumule explants of . Plant Cell, Tissue and Organ Culture 72: 281-283.

DOI: https://doi.org/10.1023/A:1022345011002

Fernando S.C., Weerakoon L.K., Karunaratne S.M. \& Santha E.S. (2000). A cost effective medium for producing embryo cultured coconut plants. Cocos 14: 45-52.

Hocher V., Verdeil J-L. \& Malaurie B. (2005). Coconut. In: Biotechnology of Fruit and Nut Crops (Ed. R.E. Litz). Biotechnology in Agriculture Series, vol 28, pp. 90-112. CABI International, Wallingford, UK. DOI: https://doi.org/10.1079/9780851996622.0090

Karimi N., Behbahani M., Dini G. \& Razmjou A. (2018). Enhancing the secondary metabolite and anticancer activity of Echinacea purpurea callus extracts by treatment with biosynthesized $\mathrm{ZnO}$ nanoparticles. Advances in Natural Sciences: Nanoscience and Nanotechnology 9(2018): 045009.

DOI: http://doi.org/10.1088/2043-6254/aaflaf

Karunaratne S., Kurukulaarachchi C. \& Gamage C. (1985). A report on the culture of embryos of dwarf coconut, L. var. nana in vitro. Cocos 3: 1-8.

DOI: https://doi.org/10.4038/cocos.v3i0.815

Karunaratne S. \& Periyapperuma K. (1989). Culture of immature embryos of coconut,Cocos nucifera L: callus proliferation and somatic embryogenesis. Plant Science 62(02):247-253.

DOI: https://doi.org/10.1016/0168-9452(89)90087-3

Kim M., Kim J., Yoon M., Choi D-I. \& Lee K-M. (2004). Origin of multicellular pollen and pollen embryos in cultured anthers of pepper (Capsicum annuum). Plant Cell, Tissue and Organ Culture 77: 63-72. DOI: https://doi.org/10.1023/B:TICU.0000016506.02796.6a

Konieczny R., Czaplicki A.Z., Golczyk H. \& Przywara L. (2003). Two pathways of plant regeneration in wheat anther culture. Plant Cell Tissue Organ Culture 73: 177-187. DOI: https://doi.org/10.1023/A:1022877807237 
Labouisse J.P., Sileye T., Morin J.P., Hamelin C., Baudouin L., Bourdeix R. \& Rouziere A. (2004). Coconut (L.) genetic improvement in Vanuatu: overview of research achievements from 1962 to 2002. Part 1: Improvement of the Vanuatu Tall by mass selection. OCL - Oleagineux, Corps Gras, Lipides 11 (4/5): 354-361.

DOI: https://doi.org/10.1051/ocl.2004.0354

Li F., Cui X., Feng Z., Du X. \& Zhu J. (2012). The effect of 2,4-D and kinetin on dedifferentiation of petiole cells in Arabidopsis thaliana. Biologia Plantarum 56: 121-125. DOI: https://doi.org/10.1007/s10535-012-0026-1

Li H., Machii H., Hagio T., Takezaki A. \& Hirabayashi T. (1999). Plant regeneration from protoplasts of Triticum aestivum L. cv. Nakasoushu. Plant Cell, Tissue and Organ Culture 58: 119-125.

DOI: https://doi.org/10.1023/A:1006359511519

Melendez-Ramirez V., Parra-Tabla V., Kevan P.G., RamirezMorillo I., Harries H., Fernandez-Barrera M. \& ZizumboVillareal D. (2004). Mixed mating strategies and pollination by insects and wind in coconut palm [Cocos nucifera $\mathrm{L}$. (Arecaceae)]: importance in production and selection. Agricultural and Forest Entomology 6(2):155-163. DOI: https://doi.org/10.1111/j.1461-9563.2004.00216.x

Metwali E.M.R. \& Al-Maghrabi O.A. (2012). Effectiveness of tissue culture media components on the growth and development of cauliflower (Brassica oleracea var. Botrytis) seedling explants in vitro. African Journal of Biotechnology 11(76): 14069-14076.

DOI: http://doi.org/10.5897/AJB12.1984

Montoro P., Etienne H., Michaux-Ferrière N. \& Carron M-P. (1993). Callus friability and somatic embryogenesis in Hevea brasiliensis. Plant Cell, Tissue and Organ Culture 33: 331-338.

DOI: https://doi.org/10.1007/BF02319019

Murashige T. \& Skoog F. (1962). A revised medium for rapid growth and bioasseys with tobacco tissue cultures. Physiologia Plantarum 15: 473-497. DOI: https://doi.org/10.1111/j.1399-3054.1962.tb08052.x

Pathirana R. \& Eason J.R. (2006). Establishment and characterization of a rapidly dividing diploid cell suspension culture of Arabidopsis thaliana L. suitable for cell cycle synchronisation. Plant Cell Tissue and Organ Culture 85(02): 125-136.

DOI:https://doi.org/10.1007/s11240-005-9057-z

Pathirana R., Frew T., Hedderley D., Timmerman-Vaughan G.\& Morgan E. (2011). Haploid and doubled haploid plants from developing male and female gametes of Gentiana triflora. Plant Cell Reports 30(06): 1055-1065.

DOI:https://doi.org/10.1007/s00299-011-1012-3

Pathirana R., Wijithawarna W.A., Jagoda K. \& Ranawaka A.L. (2002). Selection of rice for iron toxicity tolerance through irradiated caryopsis culture. Plant Cell Tissue and Organ Culture 70: 83-90.

DOI: https://doi.org/10.1023/A:1016025728740

Peng M. \& Wolyn D.J. (1999). Improved callus formation and plant regeneration for shed microspore culture in asparagus (Asparagus officinalis L.). Plant Cell Reports 18: 954-958. DOI: https://doi.org/10.1007/s002990050690
Perera P.I.P. (2003). Cytological examination of microspore development for microspore and anther culture of coconut (Cocos nucifera L.) cv Sri Lanka Tall. Cocos 15: 53-59. DOI: https://doi.org/10.4038/cocos.v15i0.2188

Perera P.I.P., Hocher V., Verdeil J-L., Doulbeau S., Yakandawala D.M.D. \& Weerakoon L.K. (2007). Unfertilized ovary: a novel explant for coconut (Cocos nucifera L.) somatic embryogenesis. Plant Cell Reports 26(1): 21-28. DOI: http://doi.org/10.1007/s00299-006-0216-4

Perera P.I.P., Perera L., Hocher V., Verdeil J-L., Yakandawala D.M.D. \& Weerakoon L.K. (2008). Use of SSR markers to determine the anther-derived homozygous lines in coconut. Plant Cell Reports 27(11): 1697-1703.

DOI:https://doi.org/10.1007/s00299-008-0592-z

Perera P.I.P., Yakandawala D.M.D., Hocher V., Verdeil J-L. \& Weerakoon L.K. (2009). Effect of growth regulators on microspore embryogenesis in coconut anthers. Plant Cell Tissue and Organ Culture 96: 171-180.

DOI:https://doi.org/10.1007/s11240-008-9473-y

Perera P.I.P., Hocher V., Weerakoon L.K., Yakandawala D.M.D., Fernando S.C. \& Verdeil J-L. (2010). Early inflorescence and floral development in Cocos nucifera L. (Arecaceae: Arecoideae). South African Journal of Botany 76(03): 482-492.

DOI: https://doi.org/10.1016/j.sajb.2010.03.006

Perera P.I.P., Motha K.F. \& Vidhanaarchchi V.R.M. (2020). Morphological and histological analysis of anther-derived embryos of coconut (Cocos nucifera L.). Plant Cell Tissue and Organ Culture 140: 685-689.

DOI: https://doi.org/10.1007/s11240-019-01762-9

Perera S.A.C.N. \& Ekanayake G.K. (2008). Characterization of Sri Lankan indigenous coconut (Cocos nucifera L.) varieties for diversity in quantitative morphology. Tropical Agriculturist 157: 25-42.

Phua Q.Y., Chin C.K., Asri A.R.M., Lam D.Y.A., Subramaniam S. \& Chew B.L. (2016). The callugenic effects of 2,4-dichlorophenoxy acetic acid (2,4-D) on leaf explants of sabah snake grass (Clinacanthus nutans). Pakistan Journal of Botany 48(2): 561-566.

Qiao M., Zhao Z.J., Song Y.G., Liu Z.H., Cao L.X., Yu Y.C., Li S. \& Xiang F.N. (2012). Proper regeneration from in vitro cultured Arabidopsis thaliana requires the microRNAdirected action of an auxin response factor. Plant Journal 71(01): 14-22.

DOI: https://doi.org/10.1111/j.1365-313X.2012.04944.x

Rattana K., Theerakulpisut P. \& Bunnag S. (2012). The effect of plant growth regulators and organic supplements on callus induction and plant regeneration in rice (Oryza sativa L.). Asian Journal of Plant Sciences 11(04): 182-189. DOI:https://doi.org/10.3923/ajps.2012.182.189

Sarvesh A., Reddy T.P. \& Kishor P.B.K. (1993). Embryogenesis and organogenesis in cultured anthers of an oil yielding crop niger (Guizotia abyssinica Cass). Plant Cell, Tissue and Organ Culture 35: 75-80.

DOI: https://doi.org/10.1007/BF00043942

SAS Institute Inc. (1999). SAS/STAT User's Guide, Version 7-1. Cary (South Carolina): SAS Institute Inc. 
Schnittger A., Schöbinger U., Stierhof Y-D. \& Hülskamp M. (2002). Ectopic B-type cyclin expression induces mitotic cycles in endoreduplicating Arabidopsis trichomes. Currunt Biology 12(05): 415-420.

DOI: https://doi.org/10.1016/S0960-9822(02)00693-0

Song H., Lou Q-F., Luo X-D., Wolukau J., Diao W-P., Qian C-T.\& Chen J-F. (2007). Regeneration of doubled haploid plants by androgenesis of cucumber (Cucumis sativus L.). Plant Cell, Tissue and Organ Culture 90: 245-254. DOI: https://doi.org/10.1007/s11240-007-9263-y

Souza J.M.M., Berkov S. \& Santos A.S. (2014). Improvement of friable callus production of Boerhaaviapaniculata Rich and the investigation of its lipid profile by GC/MS. Annals of the Brazilian Academy of Sciences 86(3): 1015-1027. DOI: https://doi.org/10.1590/0001-3765201420130098

Stella A. \& Braga M.R. (2002). Callus and cell suspension cultures of Rudgea jasminoides, a tropical woody Rubiaceae. Plant Cell Tissue and Organ Culture 68: 271276. DOI: https://doi.org/10.1023/A:1013901909797

Sushamakumari S., Asokan M.P., Anthony P., Lowe K.C., Power J.B. \& Davey M.R. (2000). Plant regeneration from embryogenic cell suspension-derived protoplasts of rubber. Plant Cell, Tissue and Organ Culture 61: 81-85. DOI: https://doi.org/10.1023/A:1006494404224
Thomas R.J., Nair R.V., Mathews C., Ajithkumar R., Sasikala M. \& Nampoothiri C.K. (2012). Studies on fruit set in coconut upon artificial pollination in various cross combinations. Indian Journal of Horticulture 69(01): 7-12.

Tripathi J.N., Muwonge A. \& Tripathi L. (2012). Efficient regeneration and transformation of plantain cv. "Gonja manjaya" (Musa spp. AAB) using embryogenic cell suspensions. In Vitro Cellular and Developmental BiologyPlant 48(02): 216-224.

DOI: https://doi.org/10.1007/s11627-011-9422-Z

Vain P., Yean H. \& Flament P. (1989). Enhancement of production and regeneration of embryogenic type II callus in Zea mays L. by AgNO3. Plant Cell, Tissue and Organ Culture 18: 143-151.

DOI: https://doi.org/10.1007/BF00047740

Vlieghe K., Boudolf V., Beemster G.T.S., Maes S., Magyar Z., Atanassova A., de Almeida Engler J., De Groodt R., Inzé D. \& De Veylder L. (2005). The DP-E2F-like gene DEL1 controls the endocycle in Arabidopsis thaliana. Current Biology 15(01): 59-63.

DOI:https://doi.org/10.1016/j.cub.2004.12.038

Xiao X-G., Charles G. \& Branchard M. (1997). Plant regeneration from cell suspensions of spinach. Plant Cell, Tissue and Organ Culture 49: 89-92.

DOI: https://doi.org/10.1023/A:1005878905306 